\title{
O LITERÁRIO EM FOTOGRAFIAS DE STEVE MCCURRY OU A ELOQUENCIA DO OLHAR EM PORTRAITS
}

\section{Patricia Tenório}

$\mathrm{Na}$ apresentação do livro Portraits (Retratos) ${ }^{20}$, o fotógrafo americano Steve McCurry revela a sua profissão de fé: Em "Retratos", eu olho para o momento de descuido, a alma essencial espreitando, a experiência gravada no rosto de uma pessoa.

É essa "alma essencial" que Steve busca, e "aprende a aguardar", nesse "desejo de conexão humana", de comunicação com o outro que "poderia ser eu". Mais adiante, na apresentação do livro, surge uma frase que me provoca.

Ao contrário do escritor, uma vez que arrumo minhas malas, não há chance para outro rascunho - ou eu tenho a foto ou não.

No site do fotógrafo ${ }^{21}$ encontro ao lado da série Portraits outra com o título Eloquence of the Eye (uma possível tradução seria A Eloquência do Olhar). A partir deste encontro imagem/palavra me questiono: "Existe alguma ligação entre as fotografias de rostos de Steve McCurry na série do livro Portraits e a literatura? Sim? Quais?"

O presente ensaio tentará estabelecer um diálogo entre a "escrita" fotográfica dessas imagens de Steve McCurry e a "escrita" literária que esses retratos provocam, incitam, questionam, inspiram em um(a) escritor(a).

\section{Steve McCurry}

Nascido a 23 de abril de 1950, em Darby, no estado da Pensilvânia, EUA, Steve McCurry é formado pela Universidade de Penn State. A princípio desejava cursar cinema ou direção de filmes, mas terminou graduando-se em artes cênicas em 1974. Interessou-se por fotografia quando trabalhava para o jornal de Penn State, The Daily Collegian. Em seguida trabalhou no Today's Post em King of Prússia, Pensilvânia, de onde saiu para aventurar-se como freelancer numa viagem à Índia. É nessa viagem que McCurry apren|||||||||||||||||||||||||||||||||||||||||||||||||||||||||||||||

20 MCCURRY, Steve. Portraits. New York: Phaidon, First Published 1999.

21 http://stevemccurry.com 
de (e apreende) o que vem a se tornar a máxima da sua técnica: a espera.

Se você espera, as pessoas irão esquecer sua câmera e a alma virá à tona sob nossos olhos.

Ao entrar disfarçado de nativo no Afeganistão pela fronteira do Paquistão, um pouco antes da invasão soviética (1979), munido apenas com uma câmera e rolos e rolos de filme escondidos em suas roupas, Steve conseguiu ser um dos primeiros fotógrafos a captar imagens do conflito, o que lhe rendeu, por sua coragem, a Medalha de Ouro do Prêmio Robert Capa de Melhor Reportagem Fotográfica no Exterior. Mas, foi com uma foto inesperada e impactante do rosto de uma menina - Menina Afegã - que McCurry tornou-se mundialmente conhecido, foto que saiu na capa da edição de junho de 1985 da revista National Geographic.

\section{A eloquência do olhar}

O livro Portraits é uma coletânea de "mais de 20 anos" de imagens, rostos que o autor confessa que "não pode esquecer", de lugares que "não quer lembrar". Com exceção de alguns retratos, tais como o do Dalai Lama ou o da Menina Afegã - em 2002, 17 anos após ser fotografada, Steve e a National Geographic conseguiram encontrar Sharbat Gula -, todas as imagens são anônimas, apenas constando cidade, país e ano em que foram tiradas. Grande parte das fotografias é de crianças que, mais desarmadas por causa da inocência própria da idade, expõem com maior liberdade a "alma essencial" tão ardorosamente procurada por McCurry.

Os retratos falam. E falam demais. No silêncio dos olhos dos retratados transitam lembranças de medo, ódio, rebeldia, tristeza, sabedoria, cansaço, fome. Podemos quase tocar nessas lembranças e, desse "quase toque", é possível materializá-las em palavras, em histórias, em poesia, poiesis como diria Aristóteles.

\section{O literário em fotografias de Steve McCurry}

Foi Aristóteles quem elevou a poiesis ao grau mais elevado da experiência humana, quando na Poética afirma a superioridade da Poesia em relação à História, sendo a História "o que aconteceu" e a Poesia "o que poderia ter acontecido"22. Esses retratos de Steve McCurry, por seu anonimato, são "possíveis acontecimentos, possíveis narrativas", que nos alcançam e convidam à investigação.

Sabemos que essas pessoas retratadas existem, mas o seu "não nome" os inscreve na lista de possíveis personagens, seres-a-vir, em que nos apropriamos de uma história e desfiamos o novelo de um enredo, que tanto pode ser real quanto não. O que importa é 
o que nos faz sentido, o que imprime "significado e significação" - característica tão própria da literatura - ao nosso momento histórico, o que desloca em nós um sentimento a ponto de precisarmos "vomitá-lo" em palavras, de maneira catártica.

Tentamos descobrir pontos de conexão entre a literatura e o ato fotográfico em Steve McCurry. Nos primórdios da criação de histórias, encontra-se a mímesis - a imitação criadora. Ela não é simplesmente a cópia do real. A mímesis é a cópia do real "transladada”, ou seja, transformada em algo superior ao real, que o abranja, o contenha, mas acrescida do saber, do conhecimento. E se formos mais atrás, na escala do tempo das formas literárias, encontraremos as formas simples, as formas simples do mito. E o mito de Medusa.

\section{O mito de Medusa}

No livro Formas simples, André Jolles afirma que "o mito é o lugar onde o objeto se cria a partir de uma pergunta e de uma resposta; (...) é o lugar onde, a partir da sua natureza profunda, um objeto se converte em criação (Schöpfung)"23.

Se tomarmos o mito grego de Medusa e o aplicarmos à série de fotografias de Steve McCurry em Portraits, observaremos o grande marco coincidente do terror. Como se os retratos fossem "transparentes" e se encaixassem na representação verbal da representação visual (ekphrasis) do mito de Medusa.

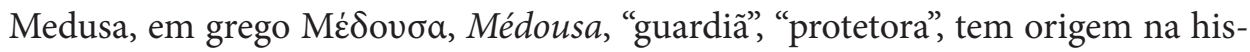
tória do monstro ctônico do sexo feminino, filha das divindades antigas Fórcis (Phorkys) e Ceto (Keto) e irmã de Esteno e Euríale - as três irmãs górgonas. Ao contrário delas, Medusa era mortal, e foi decapitada por Perseu, cuja cabeça entregou à deusa Atena que, por sua vez, a pôs em seu escudo para se "proteger" dos inimigos. Reza o mito que aquele que olhasse diretamente nos olhos de Medusa, ou da sua cabeça decapitada, petrificaria, sendo dado como morto ${ }^{24}$.

As fotografias de Steve McCurry nos impõem o terror, o impacto (e o medo) de sermos apreendidos pelo olhar. Da mesma forma que na paródia da Medusa no divertido retrato da jovem de "Los Angeles, USA, 1992", ficamos como que paralisados diante de cada imagem, chocados ou em sentimento de "compaixão" com os seres mais sofridos. "Com-paixão": nos a"paixo"namos pelo sofrimento dos outros, pela tristeza, mas também pela inocência, pela pureza da maioria das "personagens-criança” de McCurry. Elas nos desarmam. A "pergunta contendo a resposta" do mito está nelas, mas elas nos deixam uma fresta, nos impingem uma ferida que convida a nos inserir em suas histórias e a jogar "o jogo do texto".

|||||||||||||||||||||||||||||||||||||||||||||||||||||||||||||||

23 JOLLES, André. Formas simples. Tradução: Álvaro Cabral. São Paulo: Cultrix, 1976, pp. 90-91.

24 Wikipedia: http://pt.wikipedia.org/wiki/Medusa_(mitologia) 


\section{O jogo do texto e o ato de fingir}

Wolfgang Iser nos ensina que na ficção o jogo do texto é um “acordo tácito” entre o leitor e o autor ${ }^{25}$. O autor imprime uma intencionalidade em sua obra, intencionalidade esta que pode ou não ser captada pelo leitor, dependendo da sua bagagem e da sua capacidade de "imaginação criadora", da condição de "suspensão de incredulidade": um como se fosse.

Trazendo o conceito de jogo de texto de Iser para a série de fotografias em questão de McCurry, ao não conhecermos a realidade dos retratados, ao não conhecermos nem ao menos o seu "nome" - sendo o "nome" o que na Bíblia, em especial no Antigo Testamento, simboliza a vida de um homem (apagar um nome de um homem, escrito na terra, significa "matá-lo") -, ao não possuírem um "nome”, na sua maioria, Steve McCurry transforma esses retratados de "reais" em "ficcionais", podendo aí existir como se fossem outros, outros criados pela imaginação do leitor. E ao criar, "o leitor 'adota' atitudes"26, veste a pele de palavras, e, feito num teatro, representa o seu "ato de fingir".

Os trajes indianos, afegãos, italianos, tibetanos, americanos, paraguaios se acrescentam ao olhar das personagens. Enquanto o olhar nos captura, os trajes "nos vestem" feito as palavras. Paralisia e movimento. Paralisia do olhar. Movimento dos trajes. O contraditório se estabelece no silêncio das palavras de Steve McCurry.

\section{O contraditório no ato fotográfico de Steve McCurry}

O que nos atrai numa personagem de uma obra de arte, quer seja teatral, fotográfica, pictórica ou literária é a identificação com o contraditório. Somos seres contraditórios, "feitos de matéria bruta", seres "caídos", que caem e se levantam, se mostram e se escondem. O que podemos desvendar "sob o véu" dos rostos de Steve, rostos que "se abrem para a câmera", "na esperança de que no outro extremo alguém vai estar assistindo - alguém que vai rir ou sofrer com eles"27, rostos que nos impulsionam a saber mais sobre eles, a pergunta e a resposta encerrada em cada mito, na "coexistência dos contrários" encerrada em cada mito. Em cada fotografia o que nos põe em movimento é exatamente essa "coexistência dos contrários": o bem e o mal, o silêncio e a palavra, o vazio e o pleno.

A fotografia, segundo Roland Barthes, é essa "contradição nos termos", essa "pressão do indizível que quer se dizer", essa ferida, punctum, esse "acaso que, nela, me punge

25 ISER, Wolfgang. O jogo do texto, in JAUSS, Hans Robert et al. A literatura e o leitor: textos de estética da recepção. Coordenação e tradução: Luiz Costa Lima, Rio de Janeiro: Paz e Terra, 1979.

26 Idem.

27 MCCURRY, Steve. Portraits. New York: Phaidon, First Published, 1999. 
(mas também me mortifica, me fere)"28. É o impacto necessário às palavras, "palavras fictícias" porque não sei os nomes dos retratados, "palavras originais" porque abrangem o mítico, sentimentos universais da natureza humana. E então acrescentamos ao nosso repositório de saber, porque "o que acrescenta é a pergunta"29. Quando pergunto, desconstruo o simulacro, inquiro o oráculo, o determinado, o destino e o interpreto, modifico, escolho. E, mais uma vez, voltando ao jogo do texto e o alinhavando com a fotografia, enquanto "o movimento do jogo permite o 'mutuamente exclusivo", forçando o leitor "a realizar os jogos do texto e terminar o jogo ao alcançar o que considera ser seu significado"30, "a fotografia só pode significar (...) assumindo uma máscara” ${ }^{31}$. E a máscara é o sentido.

\section{O sentido da máscara}

O estudo de Daniel Jean, “T. S. Eliot Ventriloque: Létrangeté dans la voix” (“O ventríloquo em T. S. Eliot: O estranhamento na voz”), examina o primeiro período poético de T. S. Eliot, "a imagem do ventríloquo como símbolo do sujeito do poema"32. O ventríloquo afasta e protege ao mesmo tempo o poeta do seu poema, do que ele quer dizer, tirando de si a responsabilidade por sua criação.

Steve McCurry, de certa maneira, protege os retratados do que eles querem dizer de si - medo, terror, ódio, sofrimento - através da máscara do anonimato. É pela sua "não literariedade", o "não nome" que as personagens de Steve falam mais, ao mesmo tempo em que estão protegidas sob o véu do desconhecido.

"A voz é um sentido", insiste Daniel Jean. Nela se imprime a nossa particularidade, a nossa individualidade, o nosso "ser-no-mundo". Na voz se imprimem os sentimentos que não podemos disfarçar, porque a voz, a nossa própria voz, no duplo sentido da palavra "voz", não usa máscaras.

Se buscarmos a nossa voz "original", a nossa "essência", ela será nua e cristalina. Nada se interpõe quando alcançamos e habitamos a nossa "essência". Nada se interporia se alcançássemos e habitássemos o "signo original" de uma palavra, uma fotografia, uma pintura. Ele seria absoluto, pleno, inteiro. Icônico.

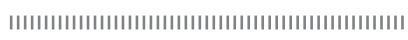

28 BARTHES, Roland. A câmara clara: nota sobre a fotografia. Tradução: Júlio Castañon Guimarães. $3^{\mathrm{a}}$ edição. Rio de Janeiro: Nova Fronteira, 2011.

29 Prof. Dr. Anco Márcio Tenório Vieira durante aulas na disciplina Bases da Teoria Literária, 2013-1, do Centro de Pós-Graduação em Letras da Universidade Federal de Pernambuco.

30 ISER, Wolfgang. O jogo do texto, in JAUSS, Hans Robert et al. A literatura e o leitor: textos de estética da recepção. Coordenação e tradução: Luiz Costa Lima, Rio de Janeiro: Paz e Terra, 1979, p. 112.

31 BARTHES, Roland. A câmara clara: nota sobre a fotografia. Tradução: Júlio Castañon Guimarães. $3^{\mathrm{a}}$ edição. Rio de Janeiro: Nova Fronteira, 2011, p. 43.

$32 \mathrm{http}: / /$ julienas.ipt.univ-paris8.fr/dela/etranger.html 
O que Steve McCurry nos convida em Portraits é atravessarmos "o papel” da fotografia pelo olhar de cada um dos retratados, tal "alcançássemos e habitássemos" a sua essência, no qual as palavras têm "significado e significação" plenos e não podem se falar, em que "a ideia coincide com a coisa em si" 33 .

\section{Kafka e a fotografia}

Imaginem a seguinte conversa entre Gustav Janouch e Franz Kafka:

- A condição prévia para a imagem é a visão.

E Kafka sorria e respondia:

- Fotografam-se coisas para expulsá-las do espírito. Minhas histórias são uma maneira de fechar os olhos ${ }^{34}$.

Existe um livro, "ficção ou não", Conversações com Kafka, de Gustav Janouch. Quem não gostaria de passear uma tarde pelas ruas e praças de Praga somente para ouvir respostas do autor de A metamorfose? A sabedoria nas suas palavras. A dor nas suas palavras.

Mas, se não posso questionar Kafka, por que não posso questionar a criança "Timbuktu, Mali, 1987", ou o que acontece por trás do menino de "Marseille, France, 1989", ou mesmo por que chora a menina de "Kathmandu, Nepal, 1979"? Toda vez que folheio Portraits encontro um novo sentido em cada olhar, porque nem sou mais "o mesmo" ser humano, nem é este rio/livro mais "o mesmo". Nas águas heraclitianas de cada leitor de imagens, de cada leitor de histórias, "metamorfoseiam-se" sentidos, significados, contextos. Vida. Aprendemos pelo "desarmamento" do olhar a estar livres da "aparência das coisas", e alcançar "as coisas em si mesmas".

\section{Olhar é um ato de escolha}

Percorremos o livro Modos de ver $^{35}$, coletânea de textos extraídos da série televisiva Ways of seeing, textos, na sua maioria, elaborados pelo escritor londrino John Berger. Nele aprendemos que "a maneira como vemos as coisas é afetada pelo que sabemos ou pelo que acreditamos", e que "só vemos aquilo que olhamos". "Olhar é um ato de escolha”, e tudo depende da intenção do nosso olhar. A história que inventamos, as lentes sob as quais sentimos o mundo, as pessoas, as coisas. Colocamos para dentro aquilo que dese-

||||||||||||||||||||||||||||||||||||||||||||||||||||||||||||||

33 http://julienas.ipt.univ-paris8.fr/dela/etranger.html Wallace Stevens: "Not Ideas about the Thing but the Thing itself".

34 BARTHES, Roland. A câmara clara: nota sobre a fotografia. Tradução: Júlio Castañon Guimarães. $3^{\mathrm{a}}$ edição. Rio de Janeiro: Nova Fronteira, 2011, p. 63.

35 BERGER, John. Modos de ver. Tradução: Lúcia Olinto. Rio de Janeiro: Rocco, 1999 - (Artemídia). 
jamos colocar para fora, e tal como "teatralizando" o nosso viver, "vestindo as pessoas e acontecimentos" com os "significados e significações" de nosso "mito pessoal", seguimos montando cenários, descrevendo cenas, tentando encontrar o "é isto" que a fotografia, por sua própria natureza, nos oferece.

No enquadramento, jogo de luz e sombra, cores dos tecidos das fotografias de Portraits, gesto e cultura se revelam em cada personagem de Steve McCurry. Eles nos lançam as respostas às perguntas do olhar de Steve, olhar que eles, com a "meia dúzia de vezes" de suas visitações, estabelecem como um vínculo de confiança ao ato fotográfico. Como se McCurry oferecesse a mão às almas presas em seus corpos e conseguisse trazê-las ao limiar do espírito/matéria, do indizível/dizível, do oculto/explícito. Steve as deixa à vontade. As personagens estão em casa. Na casa que ele as faz desejar. A casa que ele as induz habitar.

\section{Uma casa de mil portas}

O crítico, escritor e professor brasileiro Fábio Lucas nos apresenta, em O poliedro da crítica, um leque de opções para o pensamento crítico de uma obra literária. Ele afirma que cada ficção traz consigo uma rede de eventos, cuja conexão precisa ser decifrada. Repousa por detrás da trama um argumento, talvez o relato do mundo real. Constitui uma provocação ao comentário, exige uma resposta às inumeráveis questões ali adorme$\operatorname{cidas}^{36}$.

Assim, como na crítica literária, a leitura de toda obra de arte é feito uma "casa de mil portas". De lá fluem "mil” significados, "mil” possibilidades, cabendo ao "leitor ativo" - aquele equipado com as ferramentas necessárias à inquisição, à "pergunta que acrescenta" - desvendar o fio das explicações e histórias condizentes com seu contexto particular e com o do mundo que o cerca.

Steve McCurry sai "costurando" nações, culturas, situações econômicas e políticas diferentes na tentativa de reunir "o diverso no uno" da fotografia, reunir o mundo inteiro na fotografia. Tal Madame de Staël afirma - Madame de Staël (1766-1917) foi considerada uma das precursoras do comparatismo na França com o livro De la Littérature (1800): $\mathrm{O}$ que o homem fez de maior, ele o deve ao sentimento doloroso do caráter incompleto de seu destino ${ }^{37}$.

As fotografias de McCurry contêm este "elemento social de uma obra de arte". Ao mesmo tempo em que coloca as personagens interligadas, conectando-as umas às outras, conecta-as também com o leitor da imagem, esse "outro extremo" no qual "alguém vai estar assistindo", "alguém que vai rir ou sofrer com eles".

|||||||||||||||||||||||||||||||||||||||||||||||||||||||||||||||

36 LUCAS, Fábio. O poliedro da crítica. Rio de Janeiro: Calibán, 2009, p. 9.

37 BERGEZ, Daniel, in BARBÉRIS, Pierre; BERGEZ, Daniel; DE BIASI, Pierre-Marc; MARINI, Marcelle; VALENCY, Gisele. Métodos críticos para a análise literária. Tradução: Olinda Maria Rodrigues Prata. São Paulo: Martins Fontes, 2006, p. 154. 


\section{A memória: trânsito entre as diversas artes}

Em L’Arte e le Arti, Antonio Russi, a partir da suposição que "nas experiências normais, cada sentido contém, através do veículo da memória, todo os outros sentidos", conclui que "em cada arte, por via da memória, todas as outras artes estão contidas"38.

As fotografias de Steve McCurry contêm a literariedade-por-vir, uma personagem a nascer, uma história a criar forma, do exterior da fotografia ao interior do leitor de imagens, do interior do leitor de imagens ao exterior na sua escrita literária, carregando consigo seus mitos pessoais, suas lembranças, reminiscências, aquilo que foi despertado de maneira catártica por cada uma das personagens e "vomitado" através das palavras do leitor/escritor. A memória é a ponte entre os sentidos despertados, entre a fotografia e a literatura: artes diversas, mas que contêm o mesmo estatuto do "contraditório", e, por causa deste "contraditório" coabitando as suas "veias abertas", é possível a criação, a poiesis, aquilo que "realmente" poderia ter acontecido.

\section{Concluindo}

Utilizamos diversas ferramentas literárias para tentar responder às questões que nos propusemos no início deste estudo: "Existe alguma ligação entre as fotografias de rostos de Steve McCurry na série do livro Portraits e a literatura? Sim? Quais?”

Desde a forma simples do mito de Medusa, passando pela mímesis como imitação criadora, a representação verbal (possível texto) da representação visual (fotográfica), a ekphrasis, os jogos do texto pondo a experiência estética em movimento, além do como se fosse dos atos de fingir, a analogia da crítica literária com a leitura de qualquer obra de arte (seja fotográfica, pictórica ou literária) como "uma casa de mil portas", a memória como trânsito entre os diferentes sentidos e artes. Por outro lado e ao mesmo tempo, o princípio da contradição contido nas fotografias, punctum que nos "mortifica" e "fere" nessas imagens, as fotografias como máscaras que nos protegem do nosso ato criador, os atos de escolha do olhar, a teatralização do nosso viver.

Foram ferramentas utilizadas que podem ou não ter atingido seu objetivo. Mas, assim como Steve McCurry afirma que "uma vez que arrumo minhas malas, não há chance para outro rascunho", o(a) escritor(a) também se arrisca nessa escolha dos "meios para atingir os fins", na esperança de se conectar com quem o lê, e quem o lê lhe diga, mesmo que a milhas de distância ou de tempo: "É isto."

Montaigne (1533-1592), em seu ensaio da maturidade Da experiência, nos convoca a esse "longo, tortuoso, perigoso caminho" 39 do criar seu próprio estilo, plasmar a sua

||||||||||||||||||||||||||||||||||||||||||||||||||||||||||

38 RUSSI, Antonio, in PRAZ, Mario. Literatura e artes visuais. Tradução de José Paulo Paes. São Paulo: Cultrix: Ed. da Universidade de São Paulo, 1982, p. 58.

39 TENÓRIO, Patricia. As joaninhas não mentem. Rio de Janeiro: Calibán, 2006, p. 13. 
própria voz, acrescentar seu conhecimento original ao repositório do saber da humanidade.

O desejo de conhecimento é o mais natural. Experimentamos todos os meios suscetíveis de satisfazê-lo, e quando a razão não basta, apelamos para a experiência ${ }^{40}$.

A experiência da arte "alarga as nossas fronteiras". Em busca da plenitude, o ser humano translada a si mesmo do "real" a "ficção" na tentativa própria de se superar.

Mas, é preciso talento, persistência e fé para transformar imagens aparentemente simples de pessoas simples em grandes histórias. Talvez porque não tenhamos tentado o suficiente. Talvez porque não tenhamos nem ao menos retirado os pés do chão. Para voar...

Só por fraqueza nos contentamos com o que outros e nós mesmos deparamos nessa caça ao saber; os mais aptos não se satisfazem e haverá sempre caminho a percorrer para quem vier depois, e até para nós, se agirmos de outro modo. (...) Nenhum espírito generoso se detém por si mesmo, antes vai sempre para diante e além de suas forças ${ }^{41}$.

|||||||||||||||||||||||||||||||||||||||||||||||||||||||||||||

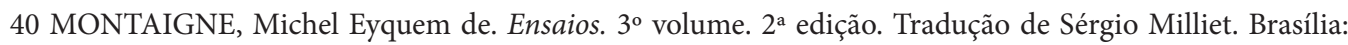
Universidade de Brasília, Hucitec, 1987, p. 348.

41 idem, p. 351. 